\title{
(Re)narrating the societal cyborg: a definition of infrastructure, an interrogation of integration
}

\author{
Paul Graham Raven* \\ University of Sheffield
}

\begin{abstract}
The call for this special issue invites us to consider "integrated infrastructure as a response to climate change". In doing so, it recapitulates a normative narrative wherein human beings play the protagonist in a struggle against climate change in the antagonistic role, and where infrastructure - integrated or otherwise - is the instrument of human action against it.

This narrative raises important questions, some of which are definitive: what exactly do we mean when we say "infrastructure"? What does it mean for an infrastructure to be "integrated"? And is the integration of infrastructure so defined desirable, or even achievable? It also begs a further question, namely: to what extent is infrastructure, integrated or otherwise, already complicit in anthropogenic climate change?

Through addressing these questions, this paper offers a functional definition of infrastructure, and goes on to problematise the question of integration in both the technical and social senses of that term, before renarrating the history of infrastructure in such a way as to reveal infrastructure not as a bulwark against anthropogenic climate change, but as the instrument through which anthropogenic climate change is produced. It concludes that the benefits of further technical integration are unproven, particularly in the absence of a comprehensive understanding of the (already significantly integrated and interdependent) systems on which we currently rely, and that further technical integration may in fact be hazardous, resulting in unexpected path-dependencies and "technological lock-ins", and further consolidating the habituation and effacement effects inherent to these systems. Furthermore, it concludes that no amount of technical integration in infrastructural systems can make any difference to climate change in and of itself, unless accompanied by the reconfiguration of consumptive practices - which is a goal far better served by the social integration of infrastructure.
\end{abstract}

Keywords: infrastructure, integration, consumption, climate change, narrative.

\section{Introduction}

In the call for this special issue, contributors were invited to consider "integrated infrastructure as a response to climate change." The issue was described as being "primarily [...] concerned with, but not limited to, the potential integration of [...] water, energy and transport" and having an urban focus through the ecosystems lens. 
"Integrated infrastructure" itself was left undefined, even as it was framed as a paradigmatic response to climate change.

As a phrase, "integrated infrastructure" isn't uncommon in the literature, though a great number of results from fields such as computer science, systems management and the managerial disciplines can be excluded immediately, as they refer to very specific integrations of very specific computer and networking hardwares and softwares. There are a number of papers dealing with "integrated infrastructure management" and "integrated infrastructure management systems" (Lemer, 1998; Halfawy et al., 2002; Halfawy, 2010; Sadek et al., 2003; Elsawah et al., 2016)), and more dealing with "integrated infrastructure planning" (Kim et al., 2012; Arts et al., 2016; Heeras et al., 2012; Zhu et al., 2015; Davidson, 1996); there are even "integrated infrastructure solutions" (Bieker et al., 2010). But in all of these, the integration being examined or advocated appears to be of the infrastructure with its management, or of the infrastructure with its planning, rather than of the infrastructures themselves.

Then there are papers dealing with integrations of specific infrastructures, particularly water and sanitation (Novotny, 2008; Bahri, 2012), and others dealing with speculative integrations of infrastructure, notably from EPSRC projects in the infrastructure theme such as "Land of the Multi-Utility Service Companies" (aka MUSCos) (Roelich et al., 2015; Roelich et al., 2013) and "All-in-One" (Karaca, Raven et al., 2013; Karaca, Camci and Raven, 2013). In none of this literature is a definition of "integrated infrastructure" attempted - perhaps because it is considered to be selfevident, or even because "the aspiration to unequivocal specification can be seen as itself conceptually and empirically counter-productive" (Harvey et al., 2016).

However, I disagree. The supposedly self-evident should never be taken on trust, particularly with regard to meaning and an unequivocal specification is demonstrably needed, if only as a way of bounding questions which tend to have expensive long-term implications for policy and polities alike. By way of example, how can we discuss the nationalisation or privatisation of infrastructure before first defining the set of valid cases upon which such a discussion might draw?

As such, it is my intent with this paper to make a first attempt at such a definition, as a way to shake up the conversation and as a way to secure it against semantic drift and mission-creep. If we wish to establish "integrated infrastructure" as a paradigmatic response to climate change, it behoves us to define our terms clearly and immediately; otherwise the term will be swiftly hollowed out and stripped of meaning, capable of meaning whatever the speaker wants it to as has already happened with "sustainability", for instance, and "smart cities".

If we want to talk about the integration of infrastructure-to be clear, I believe it to be a vital topic-we need to decide what it is we mean when we say it. I offer what follows as a point of departure for this new research journey. In order to establish a conceptual baseline, I seek in this paper to address three question-clusters, with the aim of arguing from observation and first principles as far as possible. The questions are as follows:

- Question 1: What do we mean when we say "infrastructure"? What does it do, and where does it end?

- Question 2: What do we mean when we say "integrated infrastructure"? To what extent are infrastructures already integrated, and in what ways? To what extent is further integration desirable or achievable?

- Question 3: What historical role has infrastructure played in anthropogenic climate change, and what future role might it play in mitigating or adapting to it? 
To answer this first question, I explore the etymology of the term "infrastructure", as well as its contemporary use in both the general and engineering-specialist discourses, in order to arrive at a functional definition of the term. By applying this functional definition to contemporary technological assemblages, I further identify the limits of the definition, i.e. what it is that we don't mean when we say "infrastructure".

To answer the second question, I take the two dominant definitions of the verb "to integrate", and consider how they might be understood to act upon the newly-defined category "infrastructure", before reflecting on the extent to which these two definitions of integration have been achieved, or might be desired.

To answer the third and final question, I perform a (necessarily brief) archaeology of infrastructure as so defined, to present a condensed account of its historical role in mediating between human beings and their ecological context.

Drawing upon these answers, I argue that "integrated infrastructure" is both a fait accompli (in the technological sense) and a utopian narrative (in the sociological sense), thus positioning it as a project whose social dimensions are painfully underresearched by comparison to its technical dimensions, and whose success or failure is at least as much a question of politics as it is of engineering.

\section{Question 1: What do we mean when we say "infrastructure"? What does it do, and where does it end?}

To look at the public discourse in the UK one might assume we have been talking about infrastructure for centuries, so ubiquitous is the term. This is even more true in academic and political discourses: many research councils and institutions have dedicated infrastructure themes or research programs at time of writing, and infrastructure is widely assumed to play a critical role in climate change mitigation and adaptation, sustainable development, urban densification, and other such grand civilizational challenges.

It may then come as a surprise that the term's popularity is comparatively recent by comparison with that which it tends to describe. Meaning literally "the structure(s) beneath", the term infrastructure comes to us from the French (with obvious Latin roots), arriving in English usage sometime in the early 20th century, and is thusly:

"The basic physical and organizational structures and facilities (e.g. buildings, roads, power supplies) needed for the operation of a society or enterprise." (ODO, n.d. a)

Analysis of the frequency with which the word appears in a corpus of canonical works in English (GNV, n.d.) makes it clear that the term is all but unused until the 1960s, at which point it steadily gains in currency. It is impossible to be sure without more detailed research, but it seems plausible that the word entered the discourse through the language of US-European treaties aimed at establishing the Cold War's military infrastructure, given the synchronicity of its rise in usage with the establishment and expansion of NATO, and that organisation's enduring fondness for the term.

The notion of a defensive or military infrastructure highlights a problematic duality in the way the word is used, which can also be found in the dictionary definition above. Used in a phrase such as "military infrastructure" or "social infrastructure", it is used as a relational category whose members are dependent on the modifier: "the structures enabling [the military]", "the structures enabling [society]". This sort of usage is also common in some academic disciplines such as computer science and systems 
management, wherein "infrastructure" refers to whatever hardware and connectivity necessarily underpins the operations with which they are concerned.

The term is also increasingly used as a concrete category in political discourse, suggestive of a specific set of things upon which money should (or should not) be spent. But while context-specific definitions are commonplace, the dictionary definition above is representative of the woolliness of the category: it gives examples, but doesn't explain what it is about those examples that allows them to be labelled "infrastructure".

This categorical ambiguity might be more easily illustrated with an example from paraliterary scholarship. To paraphrase slightly, the critic Damon Knight famously remarked that the generic term science fiction "means what we point at when we say it" (Knight, 2013), as a way to highlight an inherent fuzziness implicit in the definitions of literary genres: even more so now than in Knight's time, it would be very hard to make a list of the essential properties of science fiction to which all critics, authors and readers of the genre would agree, but nonetheless there is a fairly reliable consensus as to whether specific works of literature (or cinema) are science fictional or not. Following on from Knight, then, we might restate my first question as being an inquiry into infrastructure as a genre: if all of these things are infrastructures, what is it that they have in common that defines them as such?

Here is a more thorough definition of infrastructure, courtesy the Institute of Civil Engineers (ICE hereafter) (ICE, 2009):

"[Infrastructure is] the physical assets underpinning [the UK's] net- works for transport, energy generation and distribution, electronic communications, solid waste management, water distribution and wastewater treatment."

These are all large engineering projects, and they are for the most part components of networked systems, but both of those definitions allow for many other things than those in the ICE's list. For example: a pyramid is a large engineering project, but it is clearly not an infrastructure in the concrete sense that the ICE has in mind, even if it might be argued to be a religio-social infrastructure in the relative sense; likewise an ethernet LAN in a university building is a networked system, and is surely an infrastructure relative to whatever organisational activities might take place inside of it, but it is just as surely dependent on the national and global telephone and data networks external to the building for its complete function. Networkedness would therefore appear to be a necessary property of concrete infrastructure, but it is clearly not its defining property. So perhaps we might say that concrete infrastructures are those infrastructures which themselves have no infrastructure upon which they depend: those systems which serve as the final and fundamental layer of logistical support, the stuff at the very bottom of the stack?

Unfortunately, the question of infrastructural (inter)dependency turns out to be a bit more vexed than that, as shall be shown in my answering of the second question: it is more of a tangled bank than it is a systemic hierarchy. So instead I contend that a useful definition of (concrete) infrastructure must instead be rooted in functionalitywhich is to say it must define the set "infrastructure" in terms of functional properties universal to all members of that set and offer the following as a first draft thereof:

Infrastructure does two things, and two things only: the transportation and transmutation of resources. 
Some qualifications are required, though, in order to start answering the final part of the question, namely where does infrastructure end:

- Infrastructures are geographically static interventions in the landscape (or, more simply: if it can move around the map, it is not an infrastructure; indeed, maps and infrastructure have historically developed in parallel, as Guldi (2012) has shown).

- The transportation function refers to the movement of materials, energy or information through four-dimensional timespace.

- Transmutation is the process of changing the form of a resource or material in order to facilitate its distribution by the transport function (i.e. a power station and its turbines transmute coal into electrical energy prior to feeding it into the grid; a telegraph office transmutes a written or spoken message into a code which can be sent out across the wires); changes of form for extra-infrastructural purposes are not considered to be transmutations.

- The transportation function is sited predominantly on the edges of the network (where the term edges, borrowed from network theory, refers to the connections between the nodes of the network, rather than the spatial peripheries thereof).

- The transmutation function is sited predominantly on the nodes of the network.

- Simple storage can be parsed as movement in timespace with a velocity of zero (i.e. the stored resource moves through time without moving through space, e.g. warehousing is an infrastructural subcomponent).

- Sites of consumption (e.g. households, businesses) are network nodes, and can be considered as the site of manifold transmutations (e.g. food to organic waste); they can also perform the storage modality of the transportation function.

- All infrastructures are inescapably sociotechnical (i.e. all infrastructures require some degree of human operational and/or organisational activity).

This definition has been developed with physical/material resources foremost in mind, but can also describe mass-transit systems designed for the transportation of human beings; it is hoped that it may also be able to handle a more abstract conceptualisation of labour as a resource. It captures all of the category members in the ICE's list, but thanks to the limiting statement ("two things only"), excludes a great number of the higher-level systems (relative infrastructures) which depend upon them.

Furthermore, the first qualification in the list above allows us to draw a clear line between concrete infrastructure and the higher-order systems dependent upon it: the road network is a concrete infrastructure, as is the telephone and data network. But the logistics company whose vehicles travel the roads and whose organisational communications travel the phone and data networks are a relative infrastructure: such a company performs an infrastructural role for its client base, but is itself dependent upon a concrete infrastructure for its own full function.

We can also make another important distinction, namely that between an infrastructure and the devices or technologies through which that infrastructure's functionality is mediated. For example, cars and trucks are not infrastructure (because they move); instead, they are the interfaces through which certain transportation functions of a given infrastructure (the road network) are accessed. An interface is any technology which depends upon one or more supporting concrete infrastructures for its full functionality; if a tool becomes dysfunctional or nonfunctional when disconnected from one or more infrastructures, it is an interface. (I elaborate further on the interface 
concept below in my answer to the third question, by way of the contrast between interface technologies and "pure" tools.)

This leaves us with some counterintuitive but consistent conclusions. By way of illustration, let us return to the example of the ethernet LAN in a building, mentioned above. It is a static networked system (a collection of cables, switches and routers) which requires humans to interface with it using certain technologies whose full function would not be available were the network absent (network-ready computers), and its exclusive functions are the transportation and transmutation of digitised information - it fits the definition of a concrete infrastructure, in other words, and one could argue that it isn't necessarily dependent on a further, wider communications network external to the building itself (though it is, of course, interdependent upon the good function of other infrastructural systems, most notably the electricity grid).

As such, I would argue that the ethernet LAN inside a building is indeed concrete infrastructure; seen from this perspective, it is merely a subsystem of the larger network within which it is connected. This brings us to a crucial point, namely that our understanding of infrastructure is easily blurred by questions of ownership. From a purely functional perspective, the ethernet inside the building is indistinguishable from the national and global telephony networks to which it is connected. However, the building's leaseholder, the company renting the building, and the company that provides and maintains the building's network hardware may well see things very differently, which leads us to the question of infrastructural integration and interdependency.

\section{Question 2: What do we mean when we say "integrated infrastructure"? To what extent are infrastructures already integrated, and in what ways? To what extent is further integration desirable or achievable?}

Having assembled and tested a definition of "infrastructure", we next need to address the use of "integrated" as a modifier thereof. Here are the two main definitions of the verb "(to) integrate" (ODO, n.d. b); I have discarded the specifically mathematical use of the term for the sake of convenience.

1. (to) combine one thing with another to form a whole.

2. (to) bring (people or groups with particular characteristics or needs) into equal participation in or membership of a social group or institution.

This leaves us with two interpretations for "integrated infrastructure": the technical interpretation, in which one or more infrastructures are combined to form a whole (or a system-of-systems); and the social interpretation, in which certain people or groups are brought into equal participation in or membership of an institutionalised infrastructure.

\section{Integrated infrastructure: the social interpretation}

The social interpretation of "integrated infrastructure" is vexed from the outset: to which people or groups do we refer, experiencing what extent of participation (or exclusion), in which particular institutionalised system(s)? Answering these questions in detail is beyond the scope of this or any other paper, as indicated by forays into similar questions elsewhere: a fairly thorough overview of what we might term "the infrastructural turn" is provided by Harvey et al (2016), though it overlooks more recent projects wherein researchers informed by social practice theory have focussed on granular and bounded empirical accounts of the coproduction of infrastructures and 
consumptive practices (Shove et al., 2015), and on undermining the flawed behavioural models at the heart of enduringly popular technocratic/managerial theories of sociotechnical change (Shove and Walker, 2007; Shove, 2010).

All this serves strongly to suggest that I am not the first to identify the essentially ethical issue of social integration with regard to infrastructure and to further suggest that answering it is a challenge beyond the scope of this or any other paper. However, I would like to focus on one particular aspect of the question before continuing, namely what lies behind that most persistent and obfuscatory of euphemisms: who are "the stakeholders", the people or groups in question? Who makes the decisions, and how? Who actually gets consulted (rather than merely being "represented" or "considered", or just out-right ignored)? Who pays, and how much? Who profits, and how much? For whose ultimate benefit does the system work? Again, these are specific and situated questions rather than easily generalisable abstractions, and well beyond the scope of this paper - but their complexity and vexatiousness serves to illustrate the point that the social integration of infrastructure is a very long way from realisation, and that to even attempt to realise it will require a far more intimate understanding of the sociopolitics of infrastructural access and ownership than is currently available.

As such, the social interpretation of integrated infrastructure qualifies as a utopian vision but note that while to call it a utopia is to recognise it as a collective social goal which may well be impossible to fulfill, it is not necessarily to dismiss it as a pointless or naïve pipedream. As has been argued elsewhere (Raven, 2015; Levitas, 2013), utopian narratives have an important role to play in guiding social projects which are large in both the spatial and temporal sense: they are strategic visions for the long game, whose details should be constantly under amendment and refinement; an idealised future, a shared vision of tomorrow which should shape and orient the tactical steps taken in our gradual, iterative pursuit of something approximating it.

\section{Integrated infrastructure: the technical interpretation}

While this special issue addresses integrated infrastructure as a goal or aspiration, I would argue that, in the technical interpretation, infrastructure is always-already integrated: that we see it as otherwise is largely a consequence of the same questions of ownership that muddy the status of the ethernet LAN discussed above. In their contemporary incarnations, if not always their historical ones, each infrastructure is inescapably interdependent upon all of the others.

For example: there can be no coal-fired power station without railways to bring the coal from the mines, even when said mines are a matter of a few miles away; the power station's turbines and cooling systems depend on the abstraction of huge volumes of raw water, whether from aquifers or river systems; the power station's employees, and the components and consumables that keep it running, require a reliable road network to get them on site; the company that owns and operates the power station is reliant on data and telephony connections in order to not only organise its own operations (which may well be spread across multiple sites) but coordinate with those businesses and systems which are dependent upon it, and upon which it is mutually dependent.

A similar entanglement surrounds any such system one cares to analyse, and becomes more obvious when we consider entire networks rather than discreet subcomponents such as a power station. For example, a sewerage network needs reliable transport routes not just to bring employees and materials onto treatment plant sites, but to send them out to wherever in the network repairs or improvements might be required; likewise it needs communications networks to organise its internal and external operations; individual treatment plants may well recover a certain amount of 
power from sludge processing activities, but they and the pumping systems across the network require a reliable power supply in order to operate; and much as a passive and low-volume sewerage system is technically plausible, the sewerage systems we actually have are predicated on a design assumption of a per-household volume of flow whose generation is totally dependent upon said households having access to a continual (or at least reliable) supply of clean water.

A more detailed examination of how this technical entanglement came to pass can be found below, in my answer to the third question. For now, however, I think it is plain enough that the technical interpretation of "integrated infrastructure" is a fait accompli: these systems are already integrated with one another, though the precise extent to which any particular set of systems are integrated, and the organisational fidelity of that integration, remains an open question. As such, I would argue that further technical integration, while not necessarily undesirable, comes with implicit risks: to further advance technical integration in is to add further levels of complexity and emergent behaviour to a poorly-understood system-of-systems that we are already struggling to manage effectively. Further technical integration in such circumstances is potentially hazardous. We would do better to advance our technical understanding of (and our ability to manage) the system-of-systems upon which we are already totally dependent, before planning to add yet more complexity and interconnection.

\section{Question 3: What historical role has infrastructure played in anthropogenic climate change, and what future role might it play in mitigating or adapting to it?}

The premise of this special issue was "integrated infrastructure as a response to climate change". My aim for this section is to highlight the normative causality that premise implies: to posit integrated infrastructure (or indeed any other human intervention) as "a response to climate change" is to implicitly externalise climate change as a cause-less phenomenon, a deus ex machina or an externality, to use the language of classical economics. On the other hand, to posit climate change as a response to infrastructure, integrated or otherwise, is to put the boot of agency on the other foot: rather than blameless victims of a capricious climate struggling to survive through cunning technological means, this inversion makes human beings a collectivised aggressor against the environment whose capability to intervene in it is magnified many times over through their advanced technological systems.

This is a classic trick of postmodernist rhetoric, of course: neither of these two stories is any more true than the other. Indeed, the entire point is that they are both true, and that the distinction lies in the subjectivity of the question. But the story of infrastructure as a response to climate change has been told many times, and the telling has got us next to nowhere in terms of the prevention or mitigation of anthropogenic climate change. Because of its narrative structure, that story simply cannot fully admit the causal role of human beings in climate change, because it sets them in an antagonistic opposition. In this story, climate change is "the enemy", and we are the plucky protagonist, deploying ever more whizz-bang technological solutions in an escalating battle against an out-of-control environment, protected by our increasingly complex infrastructural defences. This is a limitation inherent to a particular generic narrative form, which can only be countered through the use of alternative framings.

The alternative story has been told before as well, many times, and in many different ways. But I'm going to tell it again briefly, with a little help from Donna Haraway (2006). In doing so, I want to show how infrastructure can just as easily be 
understood as the instrument through which anthropogenic climate change is produced, as opposed to understanding it as the instrument through which climate change might be defeated.

\section{A brief archaeology of infrastructure}

To give this story a central metaphor to hang from, I am going to borrow from Donna Haraway (2006) and claim that human beings have always been cyborgs. All four of Haraway's definitions of the cyborg are of interest, but the important one here is the cyborg as "a hybrid system comprising both living and inanimate material". As such, when early hunter-gatherers learned how to knap flints and sling their babies across their backs in animal skins, they became cyborgs: organic creatures extending their baseline abilities by the use of prostheses, the use of tools.

Hunter-gatherer culture was nomadic by definition. Human activity shaped the environment pretty early on, by the over-hunting of game to extinction, and by the deployment of fire. However, the necessity of following their food supplies limited the time early humans could spend intervening in the landscape to make it more convenient for them; instead, they intervened in themselves. Their only tools were what they could carry, or make to order at point of use from local resources: flint blades, wooden spears, bone needles, crude clothes of skin. These were "pure" tools: tools that do what they do in and of themselves, independent of anything other than the meanings and competencies of their makers and users; tools you could take and use anywhere. As such, hunter-gatherers can be considered to have been collectives of cyborgs: working as groups, but each possessing their own individual augmentations.

Hunter-gathering gave way gradually to agriculture, at which point that the first crude infrastructures appear. A sedentary lifestyle increased the number and diversity of tools one could manufacture and possess, because you no longer needed to carry them everywhere you went. It also reduced the opportunity cost of intervening in the environment: if a group determines that it is going to dwell in the same spot for years to come, clearing a wide path through the forest or digging irrigation ditches stops being a waste of valuable time and calories, and becomes a long-term investment enabling easier access to food, fuel or water.

But infrastructures are distinct from tools. True, they are prostheses of a sort: extensions of the baseline human ability to transport or transmute things. However, they are quite literally embedded in the landscape, which means that they are inevitably bespoke (i.e. specific to their location) and not portable. Furthermore, they enable the development of a new class of tool which would be useless or dysfunctional in their absence-which is to say that a clear, firm path through the forest was likely a prerequisite for the development of anything more advanced than the very crudest hand-cart or sledge. The distinction is perhaps easier to discern in a more modern example: in the absence of $4 \mathrm{G}$ network coverage and a compatible energy supply with which to charge it, a smartphone becomes little more than an elaborate and expensive paperweight. Hand-carts and smartphones are also tools of a sort, but they are "impure" tools, tools whose use is only possible in a certain infrastructural context: they are interfaces, in other words; devices through which infrastructural functions are accessed. And once a certain infrastructural context has been normalised, it becomes a default part of the design assumptions of new interfaces, whose uptake in turn encourages further infrastructural expansion.

But infrastructure has consequences. Infrastructure tied human communities to specific locations: convenience and free time for non- survival labour would have been a powerful influence in favour of the sedentary pattern (if only at first), but population expansion and habituation would have quickly made the new system highly obdurate 
and path-dependent, as people stopped practicing the old ways, and the situated knowledges were lost. But note that the dependency on infrastructure is subtly different to that earlier dependency on skills like knapping flint or whittling bone, and not just because the latter are skills while the former are things. Infrastructural dependency is inevitably and inescapably communal: the prostheses upon which an individual's life now depends are augmentations not of their own body, but of the collective body of the tribe or village -which is, in turn, a small part of the body of the biosphere.

The advent of infrastructure thus represents a transition in human sociotechnical relations: a shift from being a collective of cyborgs to being a cyborg collective, a plural yet singular organism, accompanied by a new, more stationary relationship to the environment. Note that while there are definitely social and political connotations to the word, the collectivism in question is significantly technological in character: humans are quite literally bound together by their habituation to infrastructural support, their fates mutually intertwined and entangled with technology, and with one another (and with the earth) through that technology. The bound cyborg collective is furthermore bound to its physical location in the global ecosystem and infrastructure is the reification of that bondage.

As discussed above, the essential function of infrastructure is the transportation and transmutation of resources. At first, the resources (and sinks) in question would have been fairly nearby to the settlement - indeed, that closeness likely provided the rationale for the settlement being there at all. But as a population expands, so too does its resource footprint. Due to the fundamentally uneven distribution of natural resources and sinks, this necessitates the gathering of resources (or the disposal of waste) ever further away from the settlement itself. This in turn leads to the development of ever larger and wider infrastructural systems and (eventually) networks, always increasing the distance at which the settlement can perform extraction or disposal in response to the settlement's ever-increasing footprint (and thus accelerating the growth of the settlement and its footprint, even as it attempts to accommodate the consequences of earlier growth).

Note that the core infrastructural function-the distribution and transmutation of resources-doesn't change at all, though the various expressions of that function become more diverse and complex. What does change over the course of infrastructural history, however-slowly at first, but with a vertiginous acceleration over the last couple of centuries-is the spatial distance between the sites of consumption and the sites of extraction and disposal that are linked by infrastructural systems. And there is a clear consequence to the increasing range, power and ubiquity of this ability to consume distant resources and send away waste: that consequence is the effacement of the observable consequences of extraction and disposal at scale.

This tale of interfaces and infrastructures and sources and sinks is a cyborg-centric take on the story of anthropogenic climate change; a phenomenon which, by definition, is caused by our collective extractions, consumptions and disposals. It is distinct from the usual normative narrative: it foregrounds infrastructure, recognising those systems as extensions of the collective bodies of human communities at various scales. In so doing, it exposes infrastructure's role in not only facilitating the extraction and disposal practices which are the cause of climate change, but also in making sure that the consequences of those practices are kept out of sight from all but the most persistent observers. It also makes a mockery of the idea that we can "solve" climate change by adding new infrastructures to the metasystem or tweaking the ones we already have, unless those new and/or improved systems were designed with the explicit aim of engineering out the habituation and effacement effects. It also emphasises that infrastructure itself has no agency independent of its creators and users, in whose 
absence it has no purpose. Infrastructure, integrated or otherwise, cannot "solve" climate change, because infrastructure doesn't produce climate change; it merely enables us to produce it ourselves, at ever more spectacular scales, and to ignore that we're doing so.

This version of the story also highlights our inescapably collective responsibility for climate change, and reveals the true and vital challenge of infrastructure in the context of climate change, which is its sociopolitical integration, not its technical integration. Integrated infrastructure is our civilisational survival suit, an array of cyborg limbs that amplify our capability to consume; to change that fact would be to make infrastructure something other than infrastructure. Further integrating infrastructures with each other will make no difference to climate change in and of itself. It is we ourselves-our practices, our politics, and our relationship with the infrastructural metasystem-that need to integrate.

The two main effects of increasing infrastructural ubiquity-a habituation to convenience resulting in the loss of small-footprint practices, and the effacement of the consequences of extraction and disposal-combine to produce what is effectively a collective life-support system, enabling communities to inhabit spaces whose local resources would be insufficient to sustain the population. The cyborg collective is bound to the physical geography of resources and sinks by the networks connecting them, and it is bound together by them, too. An individual might plausibly leave the collective and attempt to "kick the habit", but in doing so would discover that whatever resources remain in the area are already spoken for, and are inaccessible other than through the infrastructural metasystem. This means that the survival and sustainment of those within the collective happens at the expense of the possibility of individual subsistance outside of the collective, even when the individual "outside" is actually well within the purely spatial bounds of the systems in question. ${ }^{1}$

These two effects are related, in that they both expose the fundamentally mediatory role of the infrastructural metasystem. With regard to the habituation effect, infrastructure mediates the relationship of the collective with the resources distributed throughout its surrounding environment: in many contemporary cities, this mediation is close to total, meaning that almost every metabolic transaction must flow through the metasystem. With regard to the effacement effect, infrastructure itself literally stands between the consumer and site of extraction or disposal, obscuring it from sight: it is still possible for the consumer to observe the condition of a site of extraction or disposal (should they choose to do so), but those observations are also necessarily mediated by infrastructure. For the consumer to see images or read reports from a site of extraction or disposal, they must be delivered to her; for the consumer to observe a site of extraction or disposal first hand, she must use infrastructure in order to get there. In both cases, infrastructure mediates the consumer's observations of the consequences of their consumption. Indeed, concrete infrastructure can be considered as a metamedium, the fundamental material medium through which all other media must flow: information is, after all, just another resource to be transported and transmuted, whether as packets of books and newspapers, or as packets of bits. The question of which packets flow freely and, by implication, which packets flow slowly, or not at all - is therefore a question of power: he who owns the pipe controls the flow. 


\section{Conclusion}

In this paper I have argued from etymology, observation and first principles in order to answer three questions.

In response to the first question, I have offered a functional definition of concrete infrastructure, summed up as follows: "infrastructure does two things, and two things only: the transportation and transmutation of resources." I have qualified this definition in greater detail, and explored its implications with regard to what infrastructure can be considered to do, and what it can be considered not to do.

In response to the second question, I have drawn on the two dominant definitions of the verb "to integrate" to posit two possible interpretations of the phrase "integrated infrastructure", namely the technical and social interpretations. I have interrogated these definitions, and drawn on simple observation in order to claim that the technical integration of infrastructure is effectively a fait accompli, albeit a poorly-recognised one, and that the social integration of infrastructure represents a sociotechnical utopian vision which, while currently far from being realised, might act as a guiding vision for more equitable infrastructural configurations in the future.

In response to the third question, I have rehearsed a brief archaeology of infrastructure which exposes the main effects of its increasing ubiquity, namely habituation to convenience and the effacement of consequences, which in turn demonstrates that infrastructure plays a fundamentally mediatory role between humans and their environment.

This narrative further reveals the folly in proposing the (further) technical integration of infrastructure as a solution to climate change. By highlighting the cyborg hybridity of humans and their infrastructures, it reminds us that agency inheres in the human, and that infrastructures are in fact instruments through which that (collectivised) agency might be exercised-and that the exercise of that agency through those systems, which manifests fundamentally as resource extraction and waste disposal, is (and always has been) the human contribution to climate change.

Finally, by revealing the way in which infrastructure has always-already bound individuals into collectives, and trapped those collectives in a problematic relationship with space, place and resource distribution, this story suggests that the social integration of infrastructure is a more desirable goal than further technical integration: we are already bound together by infrastructure, but the relationships into which it has bound us are profoundly unequal, and the ongoing paradigm of technical integration appears only to exacerbate those inequalities. Technical integration surely has a role to play in responding to the emergent challenges of an unpredictable climate, but no amount of tweaking the system can change that system's fundamental purpose, which is to extract and provide and dispose, in an ever more convenient and frictionless fashion; indeed, further technical integration applied to a system whose existing complexities are underestimated is just as likely to result in unexpected problems of path-dependency and technological "lock-in" as it is to solve existing ones. Only through the social integration of infrastructure-through working to improve equality of access, and dismantling the structures of ownership and organisation which reproduce and profit from the effacement and habituation effects-might we hope to address the collective human profligacy which infrastructure has nurtured. 


\section{Notes}

1 So-called "off-grid" lifestyles are still possible at the peripheries of the infrastructural web, at least in theory. But those peripheries are no longer distant lands untouched by global supply chains: rather, they are dwindling pockets within the now planet-wide network, regions of sub-par connectivity analogous to neighbourhoods with poor cellphone coverage. Or, to put it another way, there is no longer an "outside" to infrastructure: there are only spaces where the network is less dense or capacious. As such, an observable lifestyle which is consciously "off-grid"-as opposed to the lifestyles of those who long to access the grid, but who are unable to do so despite their proximity to it-may in fact be an oxymoron: if we can describe it, it has in one sense already been captured and accessioned to the grid.

* Correspondence address: Paul Graham Raven, Department of Civil and Structural Engineering, The University of Sheffield, Sir Frederick Mappin Building, Mappin Street, Sheffield, S1 3JD. Email: paul@paulgrahamraven.com

\section{References}

Arts, J., Hanekamp, T., Linssen, R. and Snippe, J. (2016) Benchmarking Integrated Infrastructure Planning Across Europe - Moving Forward to Vital Infrastructure Networks and Urban Regions. Transportation Research Procedia, 14, 303-312.

Bahri, A. (2012) Integrated urban water management. GWP TEC background paper, No. 16. Stockholm: Global Water Partnership.

Bieker, S., Cornel, P. and Wagner, M. (2010) Semicentralised supply and treatment systems: integrated infrastructure solutions for fast growing urban areas. Water science and technology, 61, 11, 2905-2913.

Davidson, F. (1996) Planning for performance: requirements for sustainable development. Habitat international, 20, 3, 445-462.

Elsawah, H., Bakry, I. and Moselhi, O. (2016) Decision Support Model for Integrated Risk Assessment and Prioritization of Intervention Plans of Municipal Infrastructure. Journal of Pipeline Systems Engineering and Practice, 7, 4. Available at: http://ascelibrary.org/doi/abs/10.1061/\%28ASCE\%29PS.19491204.0000245

Google Ngram Viewer (GNV) (n.d.). Retrieved July 24, 2017. Available at: https://books.google.com/ngrams/graph?content=infrastructure \&case $\% 5 \mathrm{C}$ inse

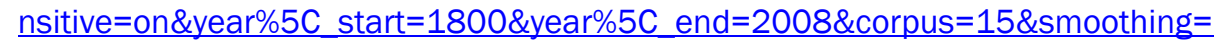
$\underline{3}$

Guldi, J. (2012) Roads to power: Britain invents the infrastructure state. Cambridge, MA: Harvard University Press.

Halfawy, M. R. (2010) Municipal information models and federated software architecture for implementing integrated infrastructure management environments. Automation in Construction, 19, 4, 433-446.

Halfawy, M.R., Pyzoha, D. and El-Hosseiny, T. (2002) An integrated framework for GISbased civil infrastructure management systems. Proceedings of the Canadian Society for Civil Engineers (CSCE) Conference, Montreal, Canada.

Haraway, D. (2006) A cyborg manifesto: Science, technology, and socialist- feminism in the late 20th century. In: The international handbook of virtual learning environments. Springer: 117-158.

Harvey, P., Bruun Jensen, C. and Morita, A. (2016) Introduction: Infrastructural Complications. Routledge. 
Heeres, N., Tillema, T. and Arts, J. (2012) Functional-spatial sustainability potentials of integrated infrastructure planning. Procedia-Social and Behavioral Sciences, 48, 2533-2544.

Institution of Civil Engineers (ICE) (2009) A National Infrastructure Investment Bank. London: Institution of Civil Engineers.

Karaca, F., Camci, F. and Raven, P.G. (2013) City blood: A visionary infrastructure solution for household energy provision through water distribution networks. Energy, 61, 98-107.

Karaca, F., Raven, P.G., Machell, J., Varga, L., Camci, F., Chitchyan, R., Boxall, J., Ulanicki, B., Skworcow, P., Strzelecka, A., et al. (2013) Single infrastructure utility provision to households: Technological feasibility study. Futures, 49, 35-48.

Kim, C., Yoo, M., Bae, J., Hong, J. and Yoon, H. (2012) Methodologies and tools for integrated infrastructure planning and rural development in South Africa. Knowledge Sharing Program.

Knight, D. (2013) Critics. In: In search of wonder: Essays on modern science fiction. Hachette UK.

Lemer, A.C. (1998) Progress toward integrated infrastructure-assets-management systems: GIS and beyond. In: Innovations in Urban Infrastructure Seminar of the APWA International Public Works Congress. Citeseer: 7-24.

Levitas, R. (2013) Utopia as method: The imaginary reconstitution of society. Springer.

Novotny, V. (2008) Sustainable urban water management. In: J. Feyen, K. Shannon, and M. Neville (eds.) Water \& Urban Development Paradigms: 19-31.

Oxford Dictionary Online (ODO) (n.d. a). Retrieved July 24, 2017, from http://www.oxforddictionaries.com/definition/english/infrastructure

Oxford Dictionary Online (ODO) (n.d. b). Retrieved July 24, 2017, from http://www.oxforddictionaries.com/definition/english/integrate

Raven, P.G. (2015) Imagining the Impossible: The Shifting Role of Utopian Thought in Civic Planning, Science Fiction, and Futures Studies. Journal of Futures Studies, 20, 2, 113-122.

Roelich, K., Knoeri, C., Steinberger, J.K., Varga, L., Blythe, P.T., Butler, D., Gupta, R., Harrison, G.P., Martin, C. and Purnell, P. (2015) Towards resource-efficient and service-oriented integrated infrastructure operation. Technological Forecasting and Social Change, 92, 40-52.

Roelich, K.E., Schmieder, T., Steinberger, J.K. and Knoeri, C. (2013) The role of governance in accelerating transition towards more integrated, service-oriented infrastructure operation.

Sadek, A.W., Kvasnak, A. and Segale, J. (2003) Integrated infrastructure management systems: Small urban area's experience. Journal of infrastructure systems, 9, 3, 98-106.

Shove, E. (2010) Beyond the ABC: climate change policy and theories of social change. Environment and Planning A, 42, 6, 1273-1285.

Shove, E. and Walker, G. (2007) CAUTION! Transitions ahead: politics, practice, and sustainable transition management. Environment and Planning A, 39, 4, 763770.

Shove, E., Watson, M., Spurling, N. and Skillington, T. (2015) Conceptualizing connections: Energy demand, infrastructures and social practices. European Journal of Social Theory, 18, 3, 274-287.

Zhu, Y., Lan, H., Ness, D.A., Xing, K., Schneider, K., Lee, S.H. and Ge, J. (2015) Transforming Rural Communities by Synergistic, Integrated and Inclusive Planning of Services and Infrastructure. In: Transforming Rural Communities in China and Beyond. Springer: 117-141. 